\title{
GOFFMAN EM ÁFRICA E ENTRE OS MÚSICOS Reflexões sobre a influência de sua obra
}

\section{Wilson Trajano Filho}

Este artigo trata, de um lado, do potencial das análises de Erving Goffman para habilitar um novo campo de estudos e dissolver (ou afirmar) algumas tensões duradouras na teoria social e, de outro, busca traçar minha própria trajetória como antropólogo sob a influência de sua obra. Primeiramente, passarei em revista o que creio serem as contribuições de Goffman para a teoria social e sua recepção entre os cientistas sociais. A seguir, destacarei alguns temas de sua obra que têm me servido de fonte de inspiração.

\section{A novidade de Goffman: ordem da interação}

Passados 25 anos de sua morte, parece não mais ser objeto de disputa a grande contribuição

Artigo recebido em junbo/2008

Aprovado em julho/2008 teórica de Goffman para as ciências sociais. Segundo vários comentadores de sua obra (Giddens, 1984, 1988; Collins, 1988; Strong, 1988, entre outros), seus trabalhos trouxeram um aporte significativo para a teoria social. Para alguns, ele foi um dos grandes sociólogos do pós-Guerra (Giddens, 1988 , p. 250); para os mais entusiastas, o maior sociólogo da segunda metade do século XX (Collins, 1988, p. 41). Certamente, para a linha de frente da disputa teórica dos anos de 1980 e 1990, que se dava em torno da constituição de uma teoria da prática, seus estudos foram fundamentais. As noções de consciência prática e de agência na teoria da estruturação de Giddens (1984) muito devem às análises de Goffman sobre as ocasiões situadas e a co-presença em que parte substancial das informações veiculadas depende da atividade corporal dos agentes (embodied information, no dizer de Goffman, 1963, p. 14). Creio também poder enxergar um pouco deste mesmo Goffman nas disposições 
incorporadas do babitus, tão central na obra de Bourdieu (1990).

Além de escritor sofisticado, Goffman foi um observador refinado e penetrante da vida dos círculos médios da sociedade norte-americana do pósGuerra, e sua obra foi marcada por uma grande inventividade conceitual. Com conceitos oriundos da linguagem ordinária, ele raramente recorria a neologismos conceituais mistificadores, como geralmente ocorre na teoria social. Além disso, ele não desenvolveu qualquer predileção para os embates teóricos explícitos com seus pares. Sua obra é repleta de notas de referência, mas estas raramente se dirigem à discussão de teorias. Pelo contrário, Goffman tinha uma predileção especial com os dados, que eram utilizados de forma criativa, quase selvagem, oriundos tanto da observação sistemática da pesquisa sociológica, como da literatura de ficção, de suas próprias observações casuais e das colunas de fait-divers ou dos consultórios sentimentais tão populares aos leitores dos jornais diários. ${ }^{1}$

Uma escrita de ricas texturas e liberada da impessoalidade aborrecida e fria das obras sociológicas convencionais, um aparato conceitual próximo da linguagem ordinária, um apreço especial por uma abordagem naturalista ${ }^{2}$ e pelos dados em detrimento às discussões mais ou menos estéreis de teorias, um talento especial para encontrar o inaudito nas regiões mais familiares da vida social, uma abertura para reformulação conceitual sempre que os dados manuseados por isto clamem, um estilo reflexivo que parece retirar prazer das experiências simultâneas mas diferentes de fazer análise e refletir sobre este fazer, tudo isso marchava um tanto contra a corrente da prática sociológica de seus contemporâneos, tudo isso contribuiu para que sua imagem fosse a de um ensaísta sensível e não um teórico sistemático. Porém, o que melhor explica a posição ímpar de Goffman na sociologia norte-americana foi o tema substantivo de seus interesses de pesquisa: a ordem da interação.

Desde o início de sua carreira, transparece com clareza a sua preocupação com o que acontece quando duas pessoas estão em situação de copresença. Em sua tese de doutorado, ele já se mostrava preocupado em descobrir a ordem social que orienta uma simples conversa entre duas pessoas em situação de co-presença (Goffman, 1999, p. 100) e procurava estabelecer uma eventual homologia entre as características da ordem social no ní- vel macrossociológico (nas instituições, na organização e estrutura dos grupos) e as do nível microssociológico ou da interação. Concluía então que os modelos disponíveis da ordem social em nível macro não enfatizavam devidamente uma característica fundamental da interação, que é a manutenção do compromisso de trabalho (working acceptance): a exigência de certa indulgência, uma espécie de "trégua provisória" a permitir a continuidade da interação perante a presença constante das ofensas (Idem, p. 106), raras em outros domínios da ordem social. ${ }^{3}$ Passados trinta anos, no discurso presidencial que deveria ter sido proferido por ele no encontro da Associação Americana de Sociologia de 1982, Goffman fez um balanço de seu percurso intelectual afirmando:

A minha preocupação durante anos foi promover a aceitação deste domínio do face a face como um domínio analiticamente viável - um domínio que poderia ser denominado, à falta de um nome mais feliz, por ordem da interação - um domínio cujo método de análise preferido é a micro-análise (1999a, p. 195).

Sua carreira pode então ser entendida como um perseverante esforço para convencer seus pares e legitimar a idéia de que a ordem da interação é um domínio autônomo de pleno direito, cujos elementos constitutivos estão mais relacionados entre si do que com elementos constitutivos de outros domínios de ordem social, como as ordens legal, política e a econômica (Idem, p. 195; ver também 1963 , p. 8). Nesse sentido, Goffman habilitou, nas palavras de Schegloff (1988, p. 90), um novo domínio de investigação sociológica, não tanto pela via do desenvolvimento de ferramentas conceituais e analíticas, mas, sobretudo, por fazer seus pares perceberem gradativamente que há algo de importante a ser investigado nos eventos banais da vida cotidiana e por saber como descrevê-los corretamente. ${ }^{4}$

Vale notar, contudo, que habilitar não é o mesmo que criar. $\mathrm{O}$ estudo das interações sociais era, antes de Goffman, uma tradição reconhecida na sociologia norte-americana. Influenciados por Simmel, Mead e William James, os sociólogos da "Escola de Chicago", por onde Goffman se doutorou, tratavam a interação social como o elemento constitutivo básico das situações sociais objetivas e únicas, estas sim objetos de descrições detalhadas. Segundo essa perspectiva, conhecida como "interacionismo simbólico", ${ }^{5}$ os indivíduos em seus encontros 
sociais seguem as leis universais da interação humana, que não são dependentes de contextos e domínios de atividade, mas simplesmente dizem respeito ao fato de que as pessoas criam atribuições para si e para os outros, tornando-as acessíveis a eles, os quais, por sua vez, combinam essas projeções para criar um self capaz de manter uma linha de ação recíproca e significativa (Gonos 1977, p. 857). Vista desse ângulo, a interação não é objeto de tematização sociológica, mas uma porta de entrada para tratar de outros assuntos, em geral, de natureza macrossociológica como, por exemplo, as formas de mensurar as relações humanas ou compreender as dinâmicas da liderança em pequenos grupos (cf. Kendon 1988, pp. 18-19). As ciências sociais tiveram, então, de esperar por Goffman para poder formular e encaminhar uma resposta à questão "como a interação é possível?" e, com isso, habilitá-la como um tema legítimo de estudo em si mesma.

Em toda sua obra, Goffman usará diversas vezes as expressões "ordem social", "ordem pública", "ordem da interação" e "ordem ritual". A ordem (não importa de qual domínio específico) é um modelo criado pelo cientista social para analisar os comportamentos reais das pessoas em termos de conformidade ou afastamentos ao que nele está estabelecido (Goffman, 1999). Cerca de dez anos depois a mesma idéia será tomada como um conjunto de normas morais que regula os modos pelos quais as pessoas buscam alcançar seus objetivos, não especificando os objetivos em si nem os padrões formados por sua coordenação e integração (Goffman, 1963, p. 8). A ordem ainda tem a natureza de modelo, mas ao excluir os tipos de objetivos buscados, que nas ordens legal, política e econômica são quase sempre prescritos, o autor acaba por desvelar uma nova faceta da ordem pública que prevalece na interação face-a-face: tratase do reconhecimento pelas pessoas da obrigação de adotar uma conduta socialmente aceitável em qualquer tipo de encontro social (cf. Burns, 1992, pp. 27-28).

Mas o que é exatamente a interação e como ela se relaciona com outras ordens? À primeira pergunta, Goffman respondeu, afirmando que é "a influência recíproca dos indivíduos sobre as ações uns dos outros, quando em presença física imediata” (1975, p. 23). Mais tarde ele procurará ser mais preciso, argumentando:
A interação social pode ser definida, num sentido estrito, como aquilo que surge unicamente em situações sociais, isto é, em ambientes nos quais dois indivíduos, ou mais, estão fisicamente em presença da resposta de um e do outro (1999a, p. 195).

Nas duas definições a co-presença física é o atributo distintivo, e dela tratarei mais adiante. $\mathrm{Na}$ última, porém, ele agrega a idéia de que as interações não acontecem no vácuo, mas em situações sociais, isto é, num ambiente espacial e temporalmente circunscrito, no interior do qual a pessoa se torna parte de um ajuntamento (gathering). Daí a importância das regiões de interação e sua distinção entre fachadas e bastidores, dos papéis discrepantes segundo as regiões (Goffman, 1975), das convenções a marcar os episódios interativos, dos colapsos e da quebra dos quadros, e dos marcadores temporais e conectivos que ligam as seqüências interativas numa serialidade temporal (Goffman, 1986). Uma situação tem início quando o monitoramento mútuo da conduta começa a ocorrer (Goffman, 1963, p. 18). ${ }^{6}$ Mas a presença de outros numa mesma situação pode ter pouca significação, daí ser importante distinguir as interações situadas, nas quais a presença do outro é um pré-requisito, das interações meramente situadas, nas quais a presença de outros é irrelevante para a atividade da pessoa (Idem, pp. 21-22). ${ }^{7}$ Goffman introduz ainda outro conceito, o de "ocasião social", que se refere a acontecimentos sociais mais amplos, também circunscritos no tempo e no espaço, providos com equipamentos fixos, como mesas, cadeiras e microfones - por exemplo, festas, conferências, sessões no parlamento, concertos de rock, saraus de música de câmara, jogos de futebol etc. A ocasião social é a motivação, o contexto social estruturante para se iniciar e terminar os ajuntamentos e as situações, e propõe, por assim dizer, padrões de conduta reconhecidos pelos participantes como apropriados. Trata-se de um conceito problemático, uma vez que gera muita ambigüidade, podendo se confundir com as noções de ajuntamento e de situação social, ou, ainda, ser considerado um mero resíduo delas. Mas as ocasiões sociais são correlatas à regulação ou à especificação das condutas (Idem, pp. 18-20), possibilitando assim o entendimento dos aspectos rotinizados da vida cotidiana (cf. Giddens, 1984, p. 71). ${ }^{8}$

A idéia de ordem como a conseqüência de um conjunto de normas morais deixa entrever a influência de Durkheim (e, em menor medida de 
Radcliffe-Brown) no pensamento goffmmaniano. Para Goffman a realidade social é antes de tudo uma realidade moral legitimada pela referência ao sagrado e ao transcendente. A conduta das pessoas tem uma dimensão não utilitária de natureza puramente ritual. Daí as práticas do "presentar-se" e do "projetar faces" (impressões positivas de si) serem por ele abordadas como parte de uma sociologia dos rituais. Na análise da figuração (face-work), Goffman argumenta que o compromisso de trabalho que faz de todos nós, em todos os lugares, participantes auto-reguladores nos encontros sociais tem uma natureza ritual, sendo nos ritos da interação que aprendemos a ser perceptivos, ter sentimentos ligados ao self e um self ligado a uma imagem positiva de si (a face), ter orgulho e dignidade no tratamento com os outros e ter consideração, sensibilidade, tato e uma maneira de se portar digna. Se as pessoas têm uma natureza humana, estes seriam os seus elementos constitutivos:

A natureza humana universal não é uma coisa muito humana. Ao adquiri-la a pessoa torna-se uma espécie de construto que não é produzido pelas propensões psíquicas internas, mas pelas regras morais impressas nela a partir do exterior. Tais regras, quando seguidas, determinam a avaliação que a pessoa fará de si e dos seus colegas-participantes dos encontros, a distribuição de seus sentimentos e os tipos de prática que empregará para manter um especificado e obrigatório tipo de equilíbrio ritual. A capacidade geral de estar ligado pelas regras morais pode até pertencer ao indivíduo, mas o conjunto particular de regras que o torna um ser humano é oriundo dos requerimentos estabelecidos pela organização ritual dos encontros sociais (Goffman, 1967 , p. 45$).^{10}$

Para alguns comentadores (cf. Bergmann, 1998, p. 286), Goffman inicia seu pensamento com base na idéia de moralidade para só posteriormente se mover rumo à noção de interação. Para outros, mais críticos (cf. Schegloff, 1988, p. 94), seu envolvimento foi quase sempre com a ordem moral implícita nos rituais e a construção e manutenção da face, só muito tardiamente ele teria de fato se debruçado sobre a organização formal dos encontros (as relações sintáticas entre os atos das diferentes pessoas em situação de co-presença [Goffman, 1967, p. 2]).

Essa parafernália de conceitos pode confundir o entendimento do que seria realmente a unidade básica de análise de sua obra. Seriam as interações face-a-face, os ajuntamentos, as situações, as ocasiões ou uma síntese disso tudo? Certamente, não é a interação em si ou as ações dos indivíduos concretos nos encontros: "não os homens e seus momentos", diz Goffman. Desde muito cedo ele se afastou das influências da psicologia social tão caras aos interacionistas simbólicos - "antes, os momentos e seus homens". Sua unidade básica de análise deve, então, incorporar o contexto, as barreiras espaciais e temporais que o circunscrevem e as regulações ou especificações da conduta por ela prescrita (formas ritualizadas da deferência, do saber portar-se e do envolver-se).

Retomo agora a idéia de co-presença, fundamental para entender a ordem da interação. Giddens (1988, p. 255) ressalva que Goffman é um teórico da co-presença, e não dos pequenos grupos (Winkin, 1999, p. 60). Este parece ser o maior dos enganos com relação à sua obra. Sua predileção pelos detalhes, seu foco na interação face-aface e seu método de microanálise muitas vezes iludem o leitor apressado levando-o a concluir que se trata de um sociólogo dos pequenos grupos ou um etnógrafo das esquinas. Nem uma coisa nem outra. As situações sociais e os ajuntamentos focalizados em nas suas primeiras obras podem ser muito grandes em termos de participantes e longos no tempo. Um megaconcerto de rock, por exemplo, pode envolver milhares de pessoas em interações focadas e não focadas, uma cerimônia pode se prolongar por dias, mas, ainda assim, são legítimos objetos de análise à la Goffman porque envolvem situações de co-presença. Aliás, ele mesmo deixou claro no prefácio de Encounters (1961) que as interações sociais que ocorrem nos ajuntamentos e nas situações sociais devem ser distinguidas do comportamento coletivo das gangues das esquinas, das multidões e dos pequenos grupos.

Os mecanismos que conferem persistência temporal aos grupos não são os mesmos que organizam a ordem da interação (Giddens, 1988, pp. 255-256). Por isso o estudo das interações em copresença inclui temas e problemas que o estudo de pequenos (ou grandes) grupos não contempla: gerenciamento dos turnos da fala, alocação de posicionamento espacial dos atores, regiões, sentimento de embaraço, manutenção da postura, tato, etiqueta, deferência, performance, práticas protetoras e defensivas, profanações cerimoniais, alienação, envolvimento dos atores, equipamentos, transformações, marcadores, quebras e ações fora dos quadros 
(frames). Esta é apenas uma parte de sua parafernália conceitual desenvolvida para entender o fato de que, quando as pessoas estão em co-presença, elas se dão conta de que estão tão perto umas das outras que podem ser observadas em tudo o que fizerem, incluindo as sensações que têm da presença dos outros. Além disso, estão próximas o bastante para serem percebidas em seu próprio sentimento de estarem sendo notadas (Goffman, 1963, p. 17). Ou, mais explicitamente, "a co-presença torna as pessoas acessíveis, disponíveis e sujeitas às outras de modo muito peculiar" (Idem, p. 22). Portanto, muito do que ocorre durante as situações de copresença se deve à própria co-presença (Goffman, 1967, p. 1).

Goffman também não foi um etnógrafo das esquinas. Apesar de sua proximidade com a antropologia, de sua proposta de fazer uma etnografia das ocasiões sociais e da admissão de ter RadcliffeBrown como fonte de inspiração, Goffman nunca fez um trabalho verdadeiramente etnográfico (com a provável exceção de sua tese de doutorado): ele nunca analisou um ritual (Strong, 1988, p. 234; Giddens, 1988, p. 254) ou uma instituição em sua totalidade. Embora seja um mestre da observação, não faz etnografia tal como fazem os antropólogos, pois parece estar sempre desconfortável pelos constrangimentos das observações concretas de eventos completos, registradas em detalhes. Sempre que pode e carece, ele adiciona coisas extras ao que está observando (Schegloff, 1988, pp. 101-106). ${ }^{11}$ Assim, a idéia de Goffman como o "etnógrafo dos terrenos ainda a descobrir" (Collins, 1988, p. 42) só pode entendida como uma metáfora: a de uma promessa que seu legado ainda pode realizar.

\section{A influência de sua obra}

Goffman foi reivindicado como par em várias esferas disciplinares durante o período que ocupou um não-lugar na sociologia. Mas permaneceu obstinadamente fiel à sua agenda inicial, voltada para o desvelamento dos princípios que organizam a experiência social da vida cotidiana. Ele ficou conhecido por propor a metáfora generalizante da vida como um drama (que posteriormente reformulou), mas é também identificado por ter trabalhado a partir de uma analogia com o jogo. Segundo Geertz (1983, pp. 24-26), etiqueta, decoro, mentira, impostura, embuste, zombaria, crime, propaganda e conversa são tomados como jogos de informação em que os atores (sozinhos ou em grupo) fazem suas jogadas, apostas e blefes. ${ }^{12}$ Formado na escola de Chicago, onde reinava o triunvirato Simmel, James e Mead, Goffman também dialogou produtivamente com Bateson, Schultz e com os etnossociólogos seguidores dessa linha de pesquisa, assim como com os sociolingüistas e antropólogos interessados na questão da linguagem (Gumperz e Hymes), além de afirmar constantemente sua lealdade a Durkheim (e em menor grau a seus seguidores da escola inglesa de antropologia social). Uma mistura e tanto, convenhamos. Goffman, de fato, lembra-me o sedento místico Riobaldo Tatarana, de Guimarães Rosa, que não perdia ocasião de religião, aproveitava de todas, bebia água de todo rio. ${ }^{13}$

Quanto à minha trajetória como antropólogo, creio ser preciso relatar de forma breve meus primeiros contatos com sua obra no sentido de contextualizar minha própria leitura e influência inspiradora de um autor tão multifacetado, com uma obra tão repleta de laminações. De partida, posso afirmar convicto que ela teve para mim o valor de uma descoberta.

Durante meu período formativo, nunca li Goffman sob a orientação de alguém mais experiente, nos vários seminários de pós-graduação que freqüentei. Meu interesse anterior, como músico, pela semiologia e por questões relativas à linguagem em uso, levou-me por acaso a ler dois artigos de Goffman publicados originalmente em meados dos anos de 1950 - "On face-work" e "Alienation from interaction" (em Goffman, 1967). De imediato fui capturado pela fineza com que ele tratava das coisas que não dão certo, que estragam nossos encontros e que nos leva a enquadrar pessoas e situações como impróprias, aborrecidas, não educadas, arrogantes ou deselegantes. Fiquei fascinado com as minúcias de sua descrição, diga-se de passagem muito mais minuciosa do que aquelas que estava aprendendo a valorizar como estudante de antropologia. Não imaginava até então que um cientista social pudesse tratar a sério coisas como regras de etiqueta, formas de deferência, mancadas, erros de performance, maneira de se portar e toda a miuçalha constitutiva das interações sociais.

A densidade destes e de outros textos de Goffman, em que descrição, análise e teoria se enlaçam 
e se confundem numa mistura artesanal, reforçou em mim a lição já aprendida com os trabalhos clássicos da antropologia: uma duradoura teoria do social nunca pode se afastar demais do mundo da vida ou, para os mais realistas, dos dados.

As questões levantadas na análise do gerenciamento das impressões, dos equipamentos usados nas interações e das regiões interativas são lições importantes que devemos levar para a pesquisa de campo, pois têm um grande significado metodológico e epistemológico para os etnógrafos. Berreman (1980) utiliza os achados goffmanianos sobre o gerenciamento das impressões para analisar as estratégias de campo do antropólogo em seus contatos com o grupo estudado, e mostra o quanto esse conhecimento é central para o pesquisador ultrapassar as dificuldades da pesquisa. ${ }^{14}$ Mas há algo que vai além da finalidade utilitária de bem concluir a atividade de pesquisa. Os dados são sempre produzidos num contexto interativo. Ao excluir tal contexto, como fazemos freqüentemente, estamos empobrecendo a análise, igualando a massa de informações e confundido ensaios com performances, brigas com brincadeiras de brigar, resistência às formas de dominação com o jogo lúdico de participações vicárias e aprendizagem com mímica.

No início de minha carreira como antropólogo, trabalhei com os processos de construção da identidade profissional dos músicos e com a constituição do mundo da música. Este trabalho é, sobretudo, uma análise dos rituais do universo musical. Ali já se fazia presente a inspiração goffmaniana no meu esforço por classificar os encontros que tinha com os músicos e como isto diferenciar o status epistemológico dos diversos "dados" produzidos nessas interações (Trajano Filho, 1984, pp. 3-20). Graças à minha experiência anterior como músico profissional, sabia, antes de iniciar a pesquisa, que questões como, por exemplo, o posicionamento espacial dos músicos no palco, a etiqueta, a deferência, o porte e a atitude exigidos nesse contexto, os erros de performance, as dificuldades nos ensaios, tudo isso constituía propriamente a seqüência ritual que culmina no concerto de música, marcado por maneiras de agir tão previamente conhecidas, como o ato de curvar-se, os gestos grandiosos, as horas certas para aplaudir etc. A análise dos bastidores ${ }^{15}$ do teatro foi fundamental para compreender como a orquestra é reafirmada nos ensaios (Idem, pp. 143-180).
Pouco tempo depois de concluir minha dissertação de mestrado tomei contato com os últimos trabalhos de Goffman, em especial seu opus magnum Frame analysis e a coletânea de artigos intitulada Forms of talk. Esses trabalhos, considerados por muitos a virada lingüística em sua sociologia, nada mais faziam do que sistematizar suas preocupações constantes com a ordem da interação, reafirmando (e este é o viés de entendimento de Goffman) sua orientação estrutural-funcionalista (muito reformulada, é verdade) oriunda de Durkheim e Radcliffe-Brown, ${ }^{16}$ além de dar uma atenção analítica e descritiva maior a um tipo especial de interação, qual seja, a forma de interação verbal corriqueira que chamamos de conversa.

Posteriormente em outros trabalhos mais uma vez deixei-me seduzir pelas idéias goffmanianas. Minha pesquisa sobre a sociedade crioula da Guiné (Trajano Filho, 1998) e, mais tarde, o estudo sobre o ciclo de cerimônias das tabancas de Cabo Verde (Trajano Filho, 2005, 2005a, 2006) foram movidos pela mesma premissa de meu trabalho anterior. $\mathrm{O}$ esforço por atribuir sentido às práticas rituais nesses dois contextos societários implicou sempre uma delimitação precisa dos tipos de interações em que as ações rituais são deslanchadas. Inspirado por Goffman, sempre procurei demarcar de modo preciso os sujeitos envolvidos nos encontros rituais e os tipos de equipamentos interativos utilizados. Sempre estive atento aos erros de performance, aos mal-entendidos, aos problemas com o envolvimento dos atores, pois esse tipo de questão é que torna as execuções rituais mais ou menos felizes. Em especial, na análise dos cortejos das tabancas caboveridanas (Trajano Filho, 2005a), faço um exercício livre de análise de quadros, procurando mostrar como tais cortejos são transformações de quadros oriundos de outros contextos societários (como, por exemplo, a peregrinação e a parada militar) e dizem respeito a questões de poder e dominação, discutindo implicitamente o problema da relação entre o nível micro dos rituais e cerimônias e o nível macro das relações coloniais.

\section{Concluindo}

Não posso dizer que reproduzo as teorias, os métodos e as ferramentas analíticas propostas por Goffman. Na realidade, é difícil separar em 
sua obra o que é teoria do que é ferramenta analítica. Conforme apontou muito bem Gamson em uma resenha de Frame analysis (1975, p. 605), não se ensina a fazer análise dos quadros do mesmo modo que se ensina a fazer análise de rede, análise estruturalista dos mitos, análise componencial ou técnicas para coletar genealogias e tantas outras disponíveis na antropologia social. Nesse sentido, Goffman mais inspira do que ensina, mais dá realce a temas e questões do que propõe teorias sistemáticas. É como uma fonte permanente de inspiração a me chamar a atenção para os detalhes mais microscópicos da vida social que me sirvo livre e criativamente de seus trabalhos.

Há, porém, um tema de natureza teórica e geral que perpassa sem ser explicitamente levantado em toda a sua obra e que ainda representa um desafio para a teoria social. Trata-se da possibilidade de uma teoria integral da sociedade e da cultura. $\mathrm{Na}$ realidade, é um problema ainda mais amplo, compartilhado por toda teoria científica.

Reduzido à sua expressão mais simples, o trabalho nas ciências (exatas ou humanas) é sempre uma tarefa interminável de cortar um fluxo de atividades em unidades mínimas e significativas, examiná-las minuciosamente e depois remontá-las, reproduzindo sob nova luz a atividade original dissecada. Esse procedimento traz sempre consigo o problema das passagens de nível, pois o olhar de perto apaga a visão da totalidade e o olhar distanciado não permite ver os detalhes. A dificuldade de realizar a passagem entre os níveis macro e micro está na raiz dos problemas enfrentados em quase todas as ciências para a elaboração de teorias parciais que complementem umas às outras, ou de uma teoria geral que tenha mais poder explicativo do que as teorias parciais estanques. $\mathrm{O}$ primeiro caso pode ser exemplificado pela dificuldade de diálogo entre micro e macro economistas, cujas teorias parciais acabam por ser campos estanques, sem que as descobertas em um plano deslanchem invenções no outro, incapazes de uma interfecundação. O segundo caso é evidente, por exemplo, na área da física, que busca desesperadamente, e sem sucesso, formular uma teoria geral que integre os quatro campos de forças da natureza. $\mathrm{Na}$ lingüística, a passagem da língua para a fala, da lingüística dos sistemas para a da pragmática tem se mostrado um obstáculo difícil de ser vencido. No âmbito das ciências sociais, o domínio das estruturas e dos sistemas tem se mostrado relativamente à parte do domínio das práticas e da ordem microscópica das interações, os tijolos que constroem o edifício social.

O trabalho de Goffman representa um esforço nessa direção, que não deve ser diminuído pela dificuldade inerente à sua natureza artesanal, inovadora e muito difícil de ser reproduzida. Desde sua tese de doutorado sobre a conduta comunicativa na ilha de Wright, defendida em 1953, ele estabeleceu uma agenda à qual se manteve fiel durante toda sua vida intelectual. Goffman desejava demonstrar que a interação tem uma natureza sui generis, independente padrões de personalidade, dos indivíduos e dos grupos. Tal como na vida política ou religiosa, a vida comunicativa é balizada por normas, que são a garantia da ordem interativa.

Parece-me não haver dúvida de que ele teve êxito em convencer seus pares da autonomia da ordem interativa e da legitimidade do seu estudo. Mas foi além disso, avançando na exploração das interfaces entre a ordem da interação e a ordem das estruturas. Porém, não elaborou uma teoria social integrada que desse conta das dimensões micro e macro da sociedade. Este é um desafio que permanece.

\section{Notas}

1 Ver Williams (1988) para uma análise dos métodos e da utilização dos dados em sua obra.

2 Ver, a guisa de ilustração do naturalismo goffmaniano, a seguinte passagem: "que espécies de animais encontramos no zôo interacional? Que plantas crescem neste jardim particular? Deixe-me fazer o inventário do que considero serem alguns exemplos de base" (Goffman, 1999a, p. 206).

3 Mais tarde, em outros trabalhos, Goffman esmiuçará a importância deste compromis-so. Ver, por exemplo, Goffman (1975, pp. 18-19).

4 Para Williams (1986, p. 366), mais do que habilitador, Goffman foi um explorador pioneiro de um vasto e novo território de investigação. Ao explorar a ordem interacional, ele tomou posse daquele terreno onde a sociedade é criada e recriada.

5 Tudo indica que Goffman não apreciava ser associado a essa corrente de pensamento, não tanto pelas supostas divergências que teria com outros autores da mesma corrente, mas pelo fato dela ser um 
rótulo criado do exterior vazio de significado (ver a este respeito extratos de sua entrevista com Winkin, 1999, pp. 240-241). Os excertos das trocas de correspondência entre ele e Dell Hymes são ilustrativos também de sua aversão aos rótulos classificadores (ver Hymes, 1984). Tudo isso, parece-me, ajuda a entender a sua própria posição peculiar no campo da sociologia norte-americana como um "inventor conservador", ou, a depender do apreço que por ele se tem, como um inclassificável ou, ainda, um gauche muito peculiar.

Em outras ocasiões, ele englobou esse mútuo monitoramento no gerenciamento das impressões (impression management), tratando-o mais detalhadamente (1975, p. 191), e abordou essa questão também no interior dos processos de figuração (facework) [1967].

7 Ver ainda a distinção entre interação focada e nãofocada, resultante da diferenciação feita acima (Goffman, 1963, pp. 24, 33-148).

A confusão suscitada entre as noções de situação, ocasião e ajuntamento talvez esteja ligada a um trânsito impreciso entre categorias emic e etic. Parece-me que as ocasiões sociais concretas são categorias emic, ao passo que as situações são etic e os ajuntamentos são, neste sentido, dúbios. Não seria possível no espaço restrito deste artigo discutir em profundidade esta questão, mas de qualquer forma a ambigüidade observada, a meu ver, será atenuada mais tarde, na sua obra de síntese, com a elaboração do conceito de "quadro" (frame).

9 Durkheim, especialmente o das Formas elementares da vida religiosa, é figura constante em todos os trabalhos de Goffman. Ele chega por vezes a atribuilhe uma aura de sacralidade, não sem certa ironia, quando, por exemplo, se refere ao pai da sociologia francesa como "Ele" (com inicial maiúscula), para buscar legitimar sua asserção de que as situações sociais são uma realidade sui generis (Goffman, 1999b, p. 150).

10 Dificilmente se encontrará uma passagem mais durkheimiana do que esta em toda sua obra. Ela serve também para afastar qualquer presunção de individualismo metodológico em sua abordagem, o que o diferencia ainda mais dos interacionistas simbólicos. Vale lembrar, a este respeito, outro excerto muito citado em Interaction ritual, que afirma: "Não os homens e seus momentos. Antes, os momentos e seus homens" $(1967$, p. 3$)$.
11 Schegloff (1988) é bastante crítico do "empiricismo" de Goffman, em especial de seu método de acrescentar elementos de sua imaginação analítica na análise de dados coletados e registrados de modo sistemático, referindo-se a uma passagem do artigo "Replies and responses", publicado posteirormente em Forms of talk (1981, p. 55) em que Goffman adiciona linhas a um diálogo registrado por um sociolingüista.

12 Poderosa conclusão, a de Geertz, mas mais chamativa do que verdadeira. Conforme apontou Burns (1992, p. 48), Goffman usou todo o repertório de imagens-analogias que tem caracterizado a reconfiguração do pensamento social (jogos, drama e texto). E apesar de sua obra ser muito marcada pelas imagens dos jogos, elas são muito mais freqüentes na acepção lúdica e imaginativa (play) do que na de estratégia (game), o que constitui conceitos bem distintos.

13 Vale comparar a projeção que este personagem faz de si mesmo com a trajetória de Goffman: "eu toda minha vida pensei por mim, forro, sou nascido diferente. Eu sou é eu mesmo. Divêrjo de todo o mundo... Eu quase que nada sei. Mas desconfio de muita coisa. O senhor concedendo eu digo: para pensar longe, sou cão mestre - o senhor solte em minha frente uma idéia ligeira e eu rastreio essa por fundo de todos os matos, amém!" (Guimarães Rosa, 1974, p. 15).

14 Berreman não deixa claro se ele tinha conhecimento da obra de Goffman antes de iniciar seu trabalho no campo, o que se deu em 1957, sendo que a primeira edição de Presentation of selfé de 1956 e teve uma circulação um tanto restrita. De qualquer maneira, mesmo em se tratando de uma reflexão post facto, as conclusões do autor são interessantes porque sugerem a improcedência da crítica de que as observações de Goffman só se aplicam ao ambiente cultural altamente competitivo e individualista das camadas médias norte-americanas. Se elas se aplicam aos Paharis do Himalaia, temos então um indicador importante de que subjacente à variedade cultural das ocasiões ou situações sociais há uma estrutura interativa comum. Variam os padrões de conduta regulados pelas ocasiões, mas há uma permanência estrutural básica. Outro ponto de interesse, no caso do desconhecimento da obra antes de sua ida a campo, é o fato de que, como atores sociais, nós temos a consciência prática das regras que estruturam as interações. 
15 Por iniciar minha análise dos bastidores do teatro como uma categoria nativa, que se refere a uma região específica do teatro, e não como categoria analítica das interações, pude ir além da perspectiva de Goffman e enfrentar um problema que os estudos de Goffman que eu até então conhecia não resolviam completamente: o das definições preestabelecidas, das normas que são transversais às ordens micro e macro. Só mais tarde pude verificar que Goffman aprofunda essa questão em Frame analysis (1986, publicado originalmente em 1974).

16 Ver sua declaração genealógica na resposta extensa que oferece às críticas de Denzin e Keller (1981) em Goffman (1981a, p. 62).

\section{BIBLIOGRAFIA}

BERGMANN. J. B. (1998), "Introduction: morality in discourse". Research on Language and Social Interaction, 31 (3-4): 279-294.

BERREMAN, G. (1980), "Teoria e método em pesquisa de campo", in A. Zaluar (org.), Desvendando máscaras sociais, Rio de Janeiro, Francisco Alves.

BOURDIEU, P. (1990), The logic of practice. Stanford, Stanford University Press.

BURNS, T. (1992), Erving Goffman. Londres, Routledge.

COLLINS, R. (1988), "Theoretical continuities in Goffman's work", in P. Drew e A. Wooton (eds.), Erving Goffman: exploring the interaction order, Boston, Northeastern University Press.

DENZIN, N. \& KELLER, C. (1981), "Frame analysis reconsidered”. Contemporary Sociology, 10 (1): 52-60.

GAMSON, W. A. (1975), "Review of Frame analysis: an essay on the organization of experience". Contemporary Sociology, 4 (6): 603-607.

GEERTZ, C. (1983), Local knowledge: further essays in interpretive anthropology. Nova York, Basic Books.

GIDDENS, A. (1984), The constitution of society: outline of the theory of structuration. Berkeley, University of California Press.

. (1988), "Goffman as a systematic social theorist", in P. Drew e A. Wooton (eds.), Erving Goffman: exploring the interaction order, Boston, Northeastern University Press.
GOFFMAN, E. (1963), Behavior in public places: notes on the social organization of gatherings. Nova York, The Free Press.

. (1961), Encounters: two studies in the sociology of interaction, Indianápolis, Bobbs-Merrill. . (1967), Interaction ritual: essays on face-toface behavior. Nova York, Anchor Books. (1975), A representação do eu na vida cotidiana, Petrópolis, Vozes . (1981), Forms of talk. Philadelphia, University of Pennsylvania Press.

(1981a), "A reply to Denzin and Keller". Contemporary Sociology, 10 (1): 60-68.

. (1986), Frame analysis: an essay on the organization of experience. Boston, Northeastern University Press.

(1999), "A ordem social e a interação", in Y. Winkin (ed.), Os momentos e os seus homens: Erving Goffman, Lisboa, Relógio d'Água.

. (1999a), "A ordem da interação", in Y. Winkin (ed.), Os momentos e os seus homens: Erving Goffman, Lisboa, Relógio d'Água.

. (1999b), "A situação negligenciada", in Y. Winkin (ed.), Os momentos e os seus homens: Erving Goffman, Lisboa, Relógio d'Água.

GONOS, G. (1977), “'Situation' versus 'frame’: the 'interactionist' and the 'structuralist' analyses of everyday life". Américan Sociological Review, 42 (4): 854-867.

GUIMARÃES ROSA, J. (1974), Grande sertão: veredas. 9 ed. Rio de Janeiro, José Olympio.

HYMES, D. (1984), "On Erving Goffman". Theory and Society, 13 (5): 621-631.

KENDON, A. (1988), "Goffman's approach to face-to-face interaction", in P. Drew e A. Wooton (eds.), Erving Goffman: exploring the interaction order, Boston, Northeastern University Press.

SCHEGLOFF, E. A. (1988), "Goffman and the analysis of conversation", in P. Drew e A. Wooton (eds.), Erving Goffman: exploring the interaction order, Boston, Northeastern University Press.

STRONG, P. M. (1988), "Minor courtesies and macro structures", in P. Drew e A. Wooton (eds.), Erving Goffman: exploring the interaction order, Boston, Northeastern University Press.

TRAJANO FILHO, W. (1984), Músicos e música no meio da travessia. Dissertação de mestrado, Universidade de Brasília. 
. (1998), Polymorphic creoledom: the "Creole" society of Guinea-Bissau. PhD dissertation, University of Pennsylvania. . (2005), "Sobre modernidade, tradições e bandeiras". Série Antropologia 370, Universidade de Brasília. . (2005a), “.Um exercício de análise de enquadramentos: os cortejos das tabancas de Cabo Verde". Texto apresentado no Seminário de Antropologia do ICS, Lisboa. . (2006), "Por uma etnografia da resistência: o caso das tabancas de Cabo Verde". Série Antropologia 408, Universidade de Brasília.

WILLIAMS, R. (1988), “Understanding Goffman's methods", in P. Drew e A. Wooton (eds.), Erving Goffman: exploring the interaction order, Boston, Northeastern University Press.

WILLIAMS, S. J. (1986), "Appraising Goffman". The British Journal of Sociology, 37 (3): 348-369.

WINKIN, Y. (1999), "Erving Goffman: retrato do sociólogo enquanto jovem", in Y. Winkin (ed.), Os momentos e os seus homens: Erving Goffman, Lisboa, Relógio d’Água. 
GOFFMAN EM ÁFRICA E ENTRE OS MÚSICOS: REFLEXÕES SOBRE A INFLUÊNCIA DE SUA OBRA

\section{Wilson Trajano Filho}

Palavras chaves: Goffman; Interação social; Rituais.

Neste trabalho discuto a contribuição de Goffman para a legitimação do estudo das interações sociais como um campo autônomo e legítimo da pesquisa social e a recepção de suas análises entre os cientistas sociais. Em seguida, descrevo a influência de sua obra na antropologia que faço.

\section{GOFFMAN IN AFRICA AND}

AMONG MUSICIANS:

REFLECTIONS ON THE INFLUENCE OF HIS WORK

Wilson Trajano Filho

Keywords: Goffman; Social interaction; Rituals.

This paper discusses the contribution of Goffman to the legitimating of the study of social interactions as an independent and legitimate field of the social research and the receipt of his analyses among social scientists. Afterwards, it describes the influence of his work in the anthropology here presented.

\section{GOFFMAN EN AFRIQUE}

ET PARMI LES MUSICIENS:

RÉFLEXIONS À PROPOS DE L'INFLUENCE DE SON GEUVRE

Wilson Trajano Filho

Mots-clés: Goffman; Interaction sociale; Rituels.

Dans ce travail, je propose un débat sur la contribution de Goffman pour la légitimation de l'étude des interactions sociales en tant que domaine autonome et légitime de recherche sociale et la réception de ses analyses parmi les scientistes sociaux. Ensuite, je décris l'influence de son œuvre dans ma propre anthropologie. 